\title{
Enhancement of antidandruff activity of shampoo by biosynthesized silver nanoparticles from Solanum trilobatum plant leaf
}

\author{
Gaurav Pant $\cdot$ Nitesh Nayak $\cdot$ R. Gyana Prasuna
}

Received: 9 May 2012/ Accepted: 9 October 2012/Published online: 23 November 2012

(C) The Author(s) 2012. This article is published with open access at Springerlink.com

\begin{abstract}
The present investigation describes simple and effective method for synthesis of silver nanoparticles via green route. Solanum trilobatum Linn extract were prepared by both conventional and homogenization method. We optimized the production of silver nanoparticles under sunlight, microwave and room temperature. The best results were obtained with sunlight irradiation, exhibiting 15-20 nm silver nanoparticles having cubic and hexagonal shape. Biosynthesized nanoparticles were highly toxic to various bacterial strains tested. In this study we report antibacterial activity against various Gram negative (Klebsiella pneumoniae, Vibrio cholerae and Salmonella typhi) and Gram positive (Staphylococcus aureus, Bacillus cereus and Micrococcus luteus) bacterial strains. Screening was also performed for any antifungal properties of the nanoparticles against human pathogenic fungal strains (Candida albicans and Candida parapsilosis). We also demonstrated that these nanoparticles when mixed with shampoo enhance the anti-dandruff effect against dandruff causing fungal pathogens (Pityrosporum ovale and Pityrosporum folliculitis). The present study showed a simple, rapid and economical route to synthesize silver nanoparticles and their applications hence has a great potential in biomedical field.
\end{abstract}

G. Pant $(\bowtie) \cdot$ N. Nayak · R. Gyana Prasuna Department of Microbiology, GITAM Institute of Science, GITAM University, Visakhapatnam, Andhra Pradesh 530045, India

e-mail: rgauravpant@gmail.com

R. Gyana Prasuna

e-mail: ravigyana@gmail.com
Keywords Antidandruff activity - Antimicrobial activity · Multidrug resistant pathogens (MDR) · Ag nanoparticle · Solanum trilobatum Linn

\section{Introduction}

Superbugs have become a serious hitch in public healthcare sector (Alanis 2005). Due to routine use of wide range antimicrobial drugs, various categories of multidrug resistant (MDR) pathogens have emerged (Davies and Davies 2010). These are the main source of nosocomial infections, blood stream infections, multidrug efflux pumps, histoplasmosis and paracoccidioidomycosis caused by Enterococcus faecalis (Saxena and Gomber 2010) Acinetobacter baumannii (Eiff et al. 2001) Pseudomonas aerogenosa (Nelson 2002) Histoplasma capsulatum (Hartmann et al. 2011) and Paracoccidioides brasiliensis (Kerr et al. 1988) respectively. These infections have a high mortality effect similar to MRSA bacteria (Chudasama et al. 2009). At this juncture the development of new techniques without involving antibiotics and hence the problem of resistance are required.

Nanoparticles and their applications are one of the recent approaches among them. Nanometer-size metallic particles show unique and considerably altered physical, chemical and biological properties compared to their macro scaled counterparts. The difference is mostly due to their high surface-to-volume ratio (Ansari et al. 2010). They exhibit transitional dimensions between bulk materials, atoms and molecules. The extensive applications they offer have warranted substantial research on them in recent years.

Silver nanoparticles exhibit size and shape-dependent properties (Rosarin and Mirunalini 2011; Sun and 
Changhua 2011) that are of interest for applications ranging from photonics (Maier et al. 2001), food packaging (Duncan 2011), catalysis (Astruc et al. 2005), sensing (Lopez-Acevedo et al. 2010), electronics (Nie and Emory 1997; Dick et al. 2001; Li et al. 2010a; Fendler 2001; Ozbay 2006), optoelectronics (Kamat 2002), and medicine (Giljohann et al. 2010; Brown et al. 2007). Biocidal or antimicrobial activity is one of the important properties of silver as it is highly toxic to most of the living cells including bacteria and fungi. These properties can also be influenced by alteration in structure and chemical-physical environment (Zhang et al. 2006). Therefore specific control on size and dimension during synthesis is important and is achieved through various methods including use of reducing agents and stabilizers ( $\mathrm{Lu}$ et al. 2007).

Solanum trilobatum Linn (Solanaceae) plant is a thorny shrub, well known in Ayurveda and Siddha system as 'Alarka' and 'Tuduvelai', respectively (Zahir et al. 2010). The decoction of entire plant is has been administered to cases of acute and chronic bronchitis. Roots, berries and flowers are used for cough. Previous reports indicated that some chemical constituent, such as solasodine and $\beta$-solamarine have been isolated from whole plant (Jahan et al. 2011). Pharmacological investigations have demonstrated that Solanum trilobatum Linn possess antioxidant, hepatoprotective, anti-inflammatory and analgesics activities. The present study has been designed to evaluate the Antidandruff activity of biosynthesized silver nanoparticles from Solanum trilobatum leaves.

\section{Materials and methods}

Chemicals and collection of plant materials

Silver nitrate solution $(99.8 \%)$ purchased from Hi Media Laboratories Pvt. Limited, Mumbai, India. $1 \mathrm{mM} \mathrm{\textrm {AgNO } _ { 3 }}$ solution was prepared and stored in amber colour bottle. The leaves of Solanum trilobatum Linn. were collected from the coastal area of Kerala, India.

Preparation of extract by conventional and homogenization method

The fresh collected leaves of Solanum trilobatum Linn were washed several times with deionised water. For conventional method, $100 \mathrm{gm}$ of finely cut Solanum trilobatum leaves were taken and boiled in $300 \mathrm{ml}$ of deionised water for $3 \mathrm{~min}$ and filtered, followed by the step of centrifugation at $10,000 \mathrm{rpm}$ for $15 \mathrm{~min}$. Finally supernatant was collected and stored at $4{ }^{\circ} \mathrm{C}$; while $100 \mathrm{~g}$ of washed leaves of Solanum trilobatum was homogenized in $300 \mathrm{ml}$ water with the help of mortar and pestle and filtered. Then the filtrate was centrifuged for $15 \mathrm{~min}$ at $10,000 \mathrm{rpm}$ and supernatant was collected and stored at $4{ }^{\circ} \mathrm{C}$.

Optimization and synthesis of silver nanoparticles under sunlight irradiation

Different concentration of leaf extracts $(1,3$ and $5 \mathrm{ml})$ were taken in conical flask separately. $10 \mathrm{ml}$ of $1 \mathrm{mM}$ $\mathrm{AgNO}_{3}$ solution was added with constant stirring and exposed under sunlight radiation and observed. The colour change of the solution was checked periodically, bioreduction of silver ions in the solution was monitored by measuring using UV-Vis spectra then the conical flask was incubated at room temperature for $48 \mathrm{~h}$. The colour change of the leaf extract from yellow to dark brown indicated the silver nanoparticles were synthesized from the leaves. The content was centrifuged at $10,000 \mathrm{rpm}$ for $15 \mathrm{~min}$. The supernatant was used for the characterization of the silver nanoparticles. The same method was performed for both conventional and homogenized method of extracts.

Synthesis of silver nanoparticles under microwave irradiation

1,3 and $5 \mathrm{ml}$ of leaf extracts were mixed separately with $10 \mathrm{ml}$ of $1 \mathrm{mM} \mathrm{AgNO}_{3}$ solution with constant stirring, and the whole mixture was kept in a domestic microwave oven (National Model NN-GD $576 \mathrm{M}$ ). The sample was subjected to several short burst of microwave irradiation at frequency of $2.45 \mathrm{GHz}$, at power output of about $100 \mathrm{~W}$ in a cyclic mode (on $15 \mathrm{~s}$, off $15 \mathrm{~s}$ ) to prevent overheating as well as aggregation of metals. The irradiation process was conducted for a minimum of 5 up to maximum of 15 cycles. The reduction of $\mathrm{Ag}^{+}$ions was monitored by sampling an aliquot $(2 \mathrm{ml})$ of the solution after 5, 7, 9, 12 and 15 cycles and measuring the UV-Vis spectra of the solution. Absorption measurements were carried out on a Genesys $10 \mathrm{UV}-\mathrm{Vis}$ spectrophotometer. The spectra were recorded at room temperature using a $1 \mathrm{~cm}$ quartz cuvette and characterized. The same was performed for both conventional and homogenized method of extracts.

Synthesis of silver nanoparticles under room temperature

$10 \mathrm{ml}$ of $1 \mathrm{mM} \mathrm{AgNO}_{3}$ solution was added to different concentration of leaf extracts $(1 \mathrm{ml}, 3 \mathrm{ml}$ and $5 \mathrm{ml})$ and incubated under room temperature for 2-3 days and observed the colour change. The colour change of the solution was checked at every $24 \mathrm{~h}$. Bioreduction of silver ions in the solution was monitored by measuring using UV-Vis spectra. The colour change of the leaf extract from 
yellow to dark brown indicated the silver nanoparticles were synthesized from the leaves. The content was centrifuged at $10,000 \mathrm{rpm}$ for $15 \mathrm{~min}$. The supernatant was used for the characterization of the silver nanoparticles. The same was performed for both conventional and homogenized method of extracts.

Production and recovery of silver nanoparticles by centrifugation

Among various concentration and methods used, sunlight irradiation method was very effective and $1 \mathrm{ml}$ of homogenized leaf extract was shown maximum synthesis of nanoparticles. Further it was chosen for bulk production as $10 \mathrm{ml}$ leaf extract in $100 \mathrm{ml}$ of $1 \mathrm{mM} \mathrm{AgNO}$. After bioreduction, the solution consisting of hydrosols of silver nanoparticles was subjected to centrifugation (Remi, Cooling Centrifuge-C-24BL) at 10,000 rpm for $15 \mathrm{~min}$, and the supernatant was discarded. The pellet formed was dissolved in $0.1 \mathrm{ml}$ of toluene water and air dried.

\section{Investigation of silver nanostructures}

UV-spectrophotometer (Model-U-2900) is used for characterization and monitoring the signature of silver nanoparticles. In particle, noble metal particles are ideal candidates for UV-Vis spectroscopy study, since they exhibit strong surface plasmon resonance absorption in the visible region and are highly sensitive to the surface modification (Mary and Inbathamizh 2012). XRD measurement was carried out by Philips X-Ray Diffractometer with Philips PW 1830 X-Ray Generator, at Department of Nuclear Physics, University of Madras, Chennai, India. The air dried nanoparticles were coated onto XRD grid and analysed for the formation of $\mathrm{Ag}$ nanoparticle at a voltage of $40 \mathrm{kV}$ and a current of $30 \mathrm{~mA}$ with $\mathrm{Cu} \mathrm{K} \alpha$ radiation $(\lambda=0.15406)$. The diffracted intensities were recorded from $10^{\prime}$ to $80^{\prime}$ of $2 \theta$ angles at room temperature (300 K). Central workshop, Department of Mechanical Engineering, Anna University, Chennai, India, helps for the SEM analysis. The study was undertaken to know the size and shape of the silver nanoparticles biosynthesized by using Solanum trilobatum. After synthesis of nanoparticles, the sample was filtered through Millipore filters of $0.2 \mu \mathrm{m}$ pore size, to remove any contaminants interfering with the SEM images. Coating of the samples with platinum was done by using the coater (JEOL, Japan, Model No.JFC-1600), finally the images of nanoparticles were obtained in Scanning Electron Microscope at applied voltage of $15 \mathrm{kV}$, magnification at $10,000 \times$ and 5,000 $\times$. FTIR investigation was performed at Department of Chemistry, Anna University, Chennai, India. The dried Ag nanoparticles were subjected to FTIR analysis by $\mathrm{KBr}$ pellet (FTIR grade) method in 1:100 ratios and spectrum was recorded in Nicolet Impact 400 FT-IR Spectrophotometer using diffuse reflectance mode operating at a resolution.

Antibacterial activity of silver nanoparticles against human pathogenic bacteria

Silver nanoparticles synthesized using Solanum trilobatum were tested for its potential antibacterial activity against few Gram positive and Gram negative human pathogens. Staphylococcus aureus, Bacillus cereus, Micrococcus luteus, Klebsiella pneumoniae, Vibrio cholerae and Salmonella typhi were used as the test organisms.

Agar diffusion assay was used to determine the antibacterial activity of silver nanoparticles from leaf extract. Sterile nutrient agar plates were prepared, latter swabbed with $24 \mathrm{~h}$ growing culture of test organisms. The wells (10 $\mathrm{mm}$ diameter) were made by using cork borer. Different concentrations $(25,50,75,100 \mu \mathrm{g})$ of the silver nanoparticles were loaded in the wells. The plates were then incubated at $37{ }^{\circ} \mathrm{C}$ for $24 \mathrm{~h}$. Antibacterial activity was measured by measuring zone inhibition.

Antifungal activity of silver nanoparticles against human pathogenic fungi-well diffusion assay method

Agar diffusion assay were used to determine the anti-fungal activity of silver nanoparticles from leaf extract. Potato Dextrose Agar (PDA) prepared was poured in the petri dish. 24 h growing culture Candida albicans and Candida parapsilosis were swabbed on it. The wells $(10 \mathrm{~mm}$ diameter) were made by using cork borer. The different concentrations $(25,50,75,100 \mu \mathrm{g})$ of the silver nanoparticles were loaded in the wells. The plates were then incubated at $37^{\circ} \mathrm{C}$ for $24 \mathrm{~h}$. The inhibition diameter was measured.

Antidandruff activity of silver nanoparticles from Solanum trilobatum leaf extract collection and maintenance of culture

Dandruff causing fungal pathogens, Pityrosporum ovale and Pityrosporum folliculitis were collected from Armatsbiotek Training and Research Institute, Chennai, India and maintained on Leeming Notman and Potato Dextrose Agar, slant and broth.

Agar diffusion assay is used widely to determine the antiDandruff activity of silver nanoparticles from leaf extract. The technique works well with defined inhibitors. Potato Dextrose Agar (PDA) prepared was poured in the petri dish. Twenty-four hours broth culture of Pityrosporum ovale and Pityrosporum folliculitis were swabbed over the surface of Potato Dextrose Agar. All the active nanoparticles and the 
shampoos were dissolved in water at $10 \mathrm{mg} / \mathrm{ml}$ concentration. A circle of $10 \mathrm{~mm}$ diameter was cut at the surface of the agar and $100 \mu \mathrm{l}$ of the above prepared samples were loaded on the well. Plates were incubated at $37{ }^{\circ} \mathrm{C}$ for 3-5 days. After incubation the zone was measured using zone measuring scale and recorded.

\section{Results and discussion}

Biosynthesis of silver nanoparticles

Plant materials were collected and plant leaf extraction was prepared both by conventional (Govindarajan et al. 2008) and homogenized method (Fig. 1). Biosynthesis of silver nanoparticles by the filtrate of Solanum trilobatum was confirmed by change in the color of the filtrate to brown after addition of silver nitrate (Fig. 2). This arises due to excitation of surface plasmon vibrations in silver nanoparticles (Govindaraju et al. 2008). As the Solanum trilobatum plant leaf extract was mixed in the aqueous solution of the silver ion complex, it started to change the

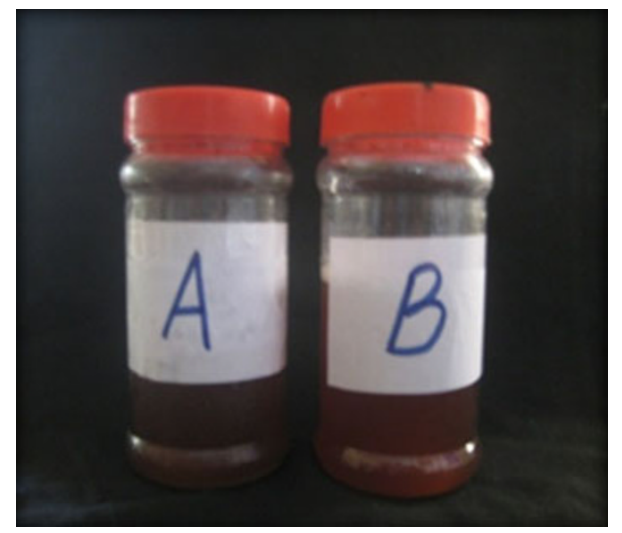

Fig. 1 Plant leaf extracts a conventional method. b Homogenization method

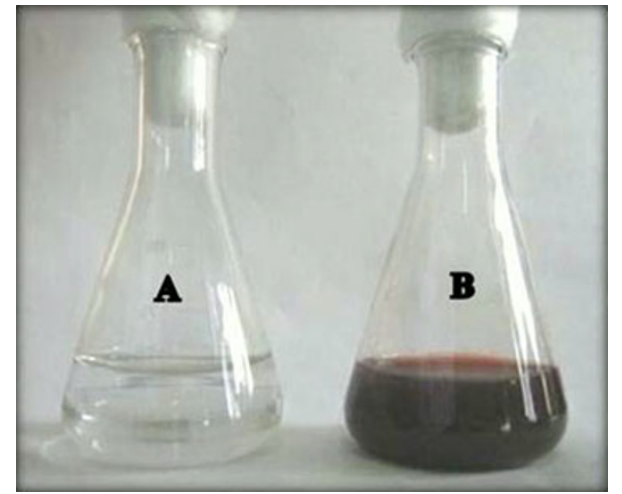

Fig. 2 Synthesis of silver nanoparticle $\mathbf{a}$ before, $\mathbf{b}$ after reaction color from watery to yellowish brown due to reduction of silver ion, which indicated formation of silver nanoparticles (Kanchana et al. 2010, 2012).

Investigation of Solanum trilobatum synthesized silver nanoparticle

The bioreduction of $\mathrm{Ag}^{+}$with examination of size and shape of nanoparticles in aqueous suspensions was monitored by periodic sampling of the reaction mixture at regular intervals by using UV-Vis spectroscopy ( $\mathrm{Wu}$ et al. 2010; Raghunandan et al. 2011). Control flasks maintained with silver nitrate solution (without culture filtrates) did not show any change of color and its absorbance maximum was found to be at $340 \mathrm{~nm}$, which is specific for silver nitrate solution. Whereas sunlight irradiated reaction mixture consisted of culture filtrate with silver nitrate (Fig. 3) showed a strong characteristic absorbance peak at around $430 \mathrm{~nm}$, broadening of peak indicated that the particles are

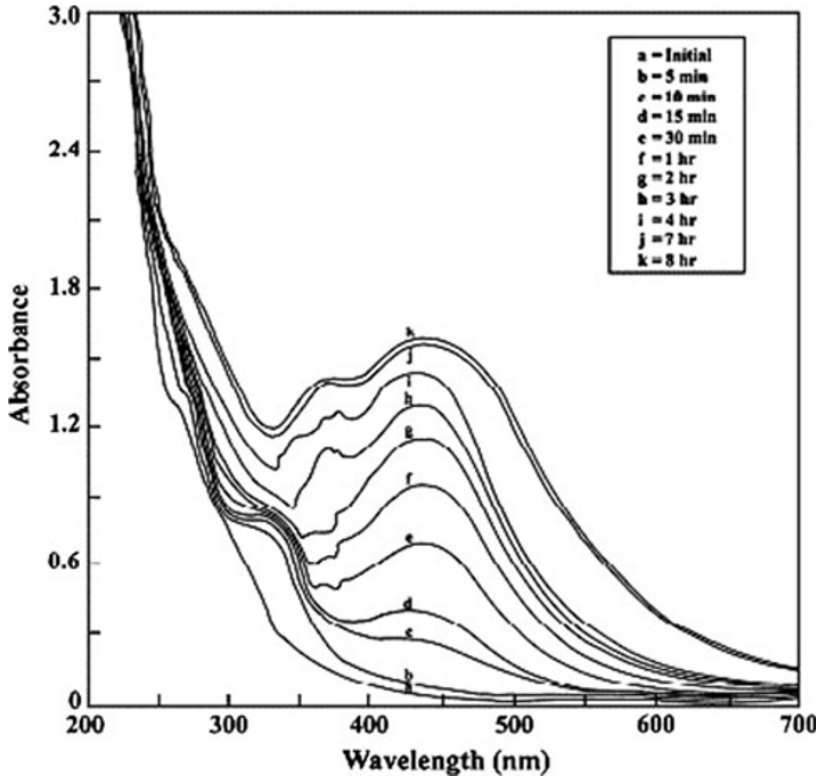

Fig. 3 UV-Vis spectra of silver nanoparticle

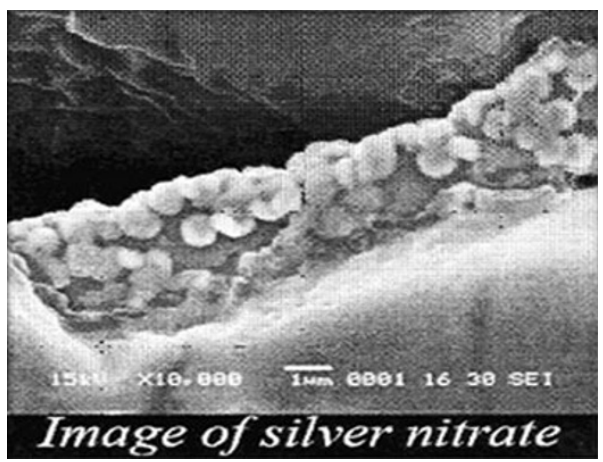

Fig. 4 SEM analysis of silver nitrate 

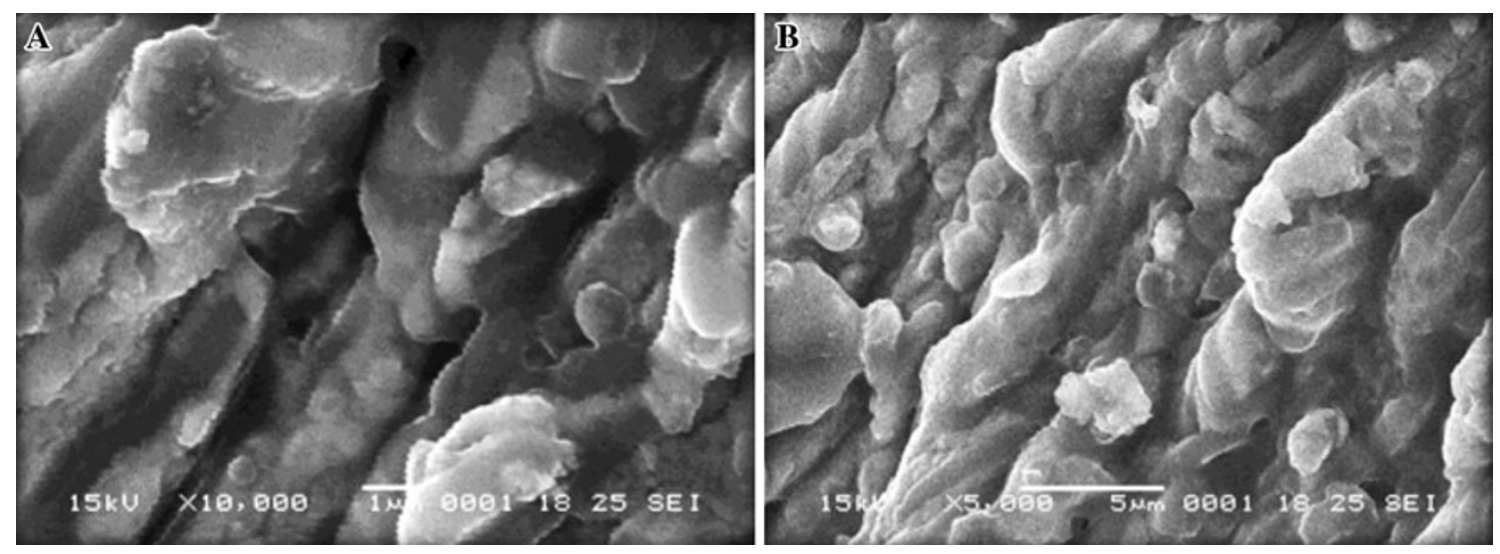

Fig. 5 SEM analyses of a silver nanoparticle in $1 \mu \mathrm{m}$ and $\mathbf{b}$ silver nanoparticle $5 \mu \mathrm{m}$

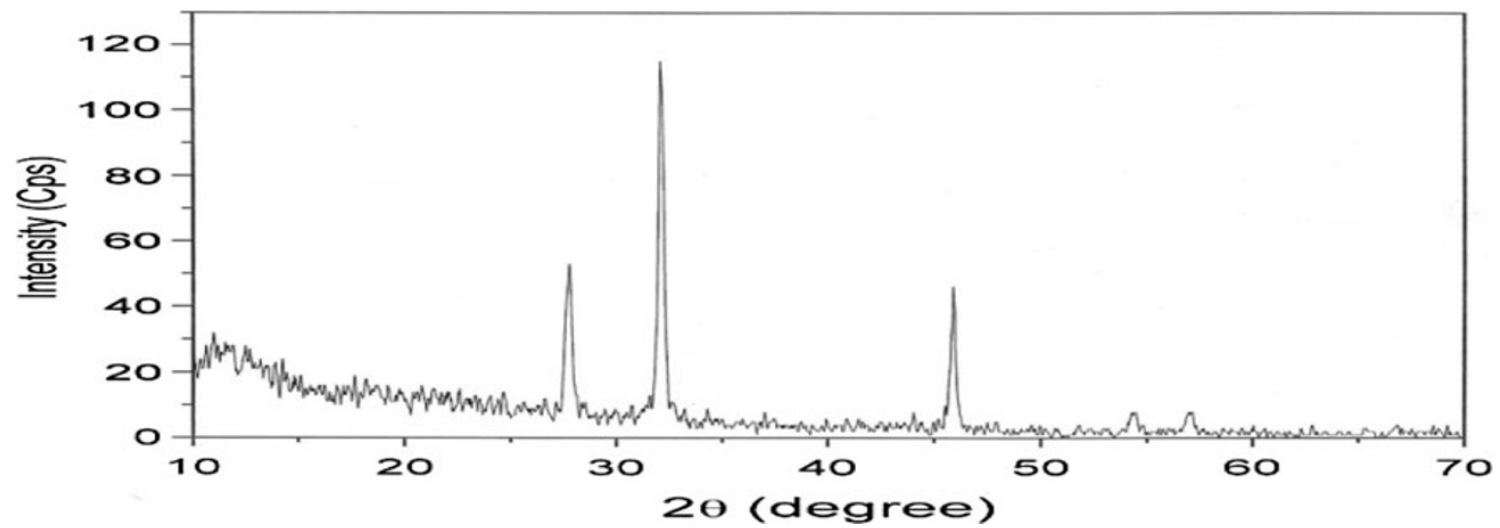

Fig. 6 The XRD pattern of the silver nanoparticles

polydispersed. Analysis by spectrophotometer was made up to $8 \mathrm{~h}$ with all the combinations, in which homogenized method followed by sunlight irradiation optimize the best results therefore used for further studies.

Scanning electron microscopic analysis of the silver nitrate solution (Control) and reduced form of silver nitrate solution, clearly distinguishable owing to their size difference. It is clear from the SEM pictures that control silver nitrate particles are more than $1,000 \mathrm{~nm}$ size, where as silver particles in the bioreduced colloidal suspensions measured 15-20 nm in size. Figure 4 is the SEM of silver nitrate and Fig. 5 is the SEM of bioreduced silver nitrate. The SEM image showing the high density silver nanoparticles synthesized by the Solanum trilobatum plant leaf and confirmed the development of silver nanostructures.

The biosynthesised silver nanostructure employing Solanum trilobatum plant leaf extract was further demonstrated and confirmed by the characteristic peaks observed in the XRD image. The XRD pattern showed intense peaks at $28.18^{\circ}, 38.18^{\circ}, 46.18^{\circ}, 64.1^{\circ}$ and can be indexed the angle vales of (111), (200), (220), (240) crystalline planes of cubic $\mathrm{Ag}$ in the whole spectrum of $2 \theta$ value ranging from 10 to 80 (Marimuthu et al. 2011; Bee et al. 2002; Cihlar et al. 1999). This analysis revealed that average size of the particles synthesized was $15 \mathrm{~nm}$ derived from the FWHM of peak corresponding to 111 plane with size range 10 to $50 \mathrm{~nm}$ with cubic and orthorhombic crystals. The high peaks in the analysis indicate the active silver composition with the indexing (Fig. 6). The typical XRD pattern revealed that the sample contains a mixed phase (cubic and hexagonal) structures of silver nanoparticles.

The presence of some functional group as revealed by IR spectral is shown in Fig. 7. The FTIR spectral analyses of silver nanoparticles show certain common absorption band at $3,398 \mathrm{~cm}^{-1}$ is a characteristic of hydroxyl $v(\mathrm{O}-\mathrm{H})$ and $v(\mathrm{~N}-\mathrm{H})$ vibrational frequency which are interchangeable. A common 3 vibrational peak between 2,899 and $2,977 \mathrm{~cm}^{-1}$ are characteristic of a $v(\mathrm{C}-\mathrm{H})$ symmetrical vibration of saturated hydrocarbon. The vibrational frequency $v(\mathrm{C}-\mathrm{O})$ was observed in the spectra of the extracts at 1,047 and $1,087 \mathrm{~cm}^{-1}$. Deviation from this region to a higher wave number was observed which is indicative of a secondary amide. These peaks were sharper than the $v(\mathrm{O}-\mathrm{H})$ peaks due to reduction in hydrogen bonds which increases with electronegativity. Vibrational peaks at $1,654 \mathrm{~cm}^{-1}$ in extract signify the possibility of an aromatic compound 


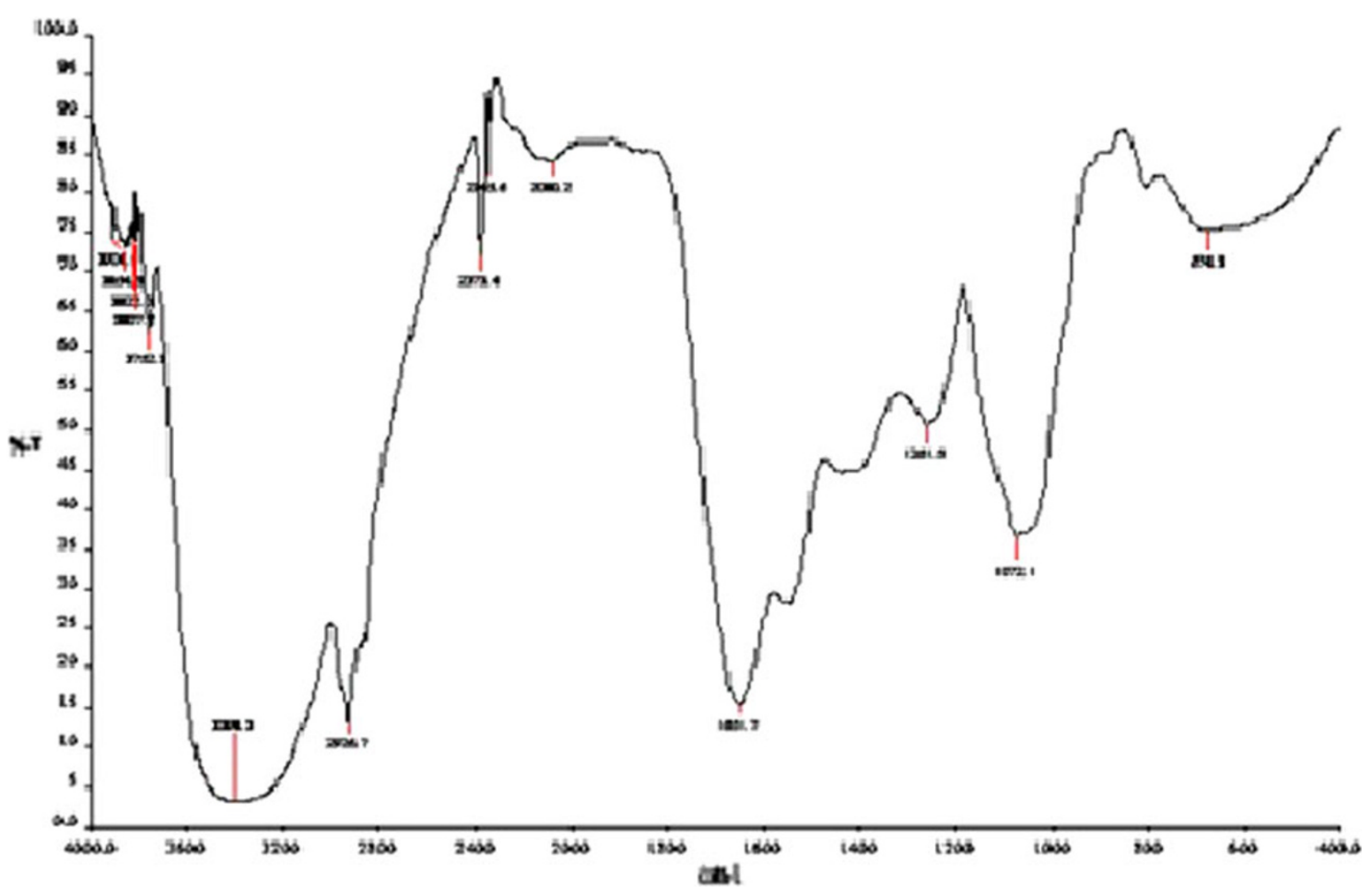

Fig. 7 The FTIR spectrum of the silver nanoparticles

(Bahgat and Ragheb 2007). Based on the physical state (oily) of the extracts and the characteristic features of the infrared vibrational peaks in the spectra, terpenoids, long chain fatty acids and secondary amine derivatives are possible compounds in the particles.

FTIR absorption spectra of silver nanoparticles shows absorbance bands (before bioreduction) are observed in the region of $500-2,000 \mathrm{~cm}^{-1}$ are 1,697, 1,618, 1,514, 1,332, $1,226 \mathrm{~cm}^{-1}$. These absorbance bands are known to be associated with the stretching vibrations for $-\mathrm{CC}-\mathrm{CO}$, $\mathrm{CC}-$ [(in-ring) aromatic], $-\mathrm{C}-\mathrm{C}-[$ (in-ring) aromatic $], \mathrm{C}-\mathrm{O}$ (esters, ethers) and $\mathrm{C}-\mathrm{O}$ (polyols), respectively (Edwards et al. 2003). In particular, the $1,226 \mathrm{~cm}^{-1}$ band arises most probably from the $\mathrm{C}-\mathrm{O}$ group of polyols such as hydroxyflavones and catechins (Begum et al. 2009). The total disappearance of this band after the bioreduction may be due to the fact that the polyols are mainly responsible for the reduction of $\mathrm{Ag}$ ions, whereby they themselves get oxidized to unsaturated carbonyl groups leading to a broad peak at $1,650 \mathrm{~cm}^{-1}$ (for reduction of $\mathrm{Ag}$ ).

Antibacterial activity of silver nanoparticles against human pathogenic bacteria

Zone of inhibition in the plate showed that silver nanoparticles synthesized using Solanum trilobatum have the antibacterial activity against all test pathogens namely Staphylococcus aureus, Bacillus cereus, Micrococcus

luteus, Klebsiella pneumoniae, Vibrio cholerae and Salmonella typhi (Citarasu et al. 2003; Galina et al. 2009). On comparison with the silver nitrate and filtrate silver nanoparticles outperformed in the bactericidal effect (Fig. 8).
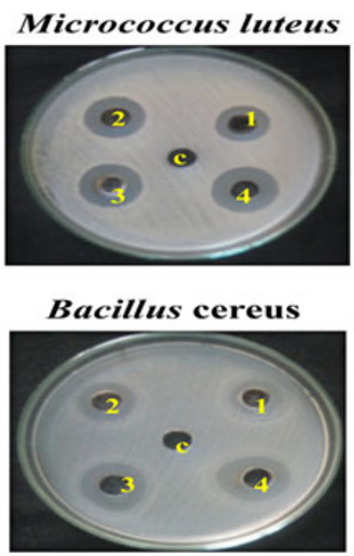

Staphylococcus aureus

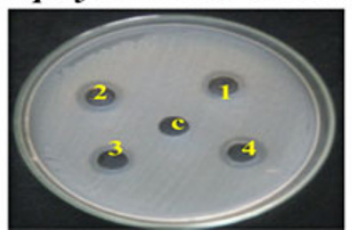

Fig. 8 Antibacterial activity of silver nanoparticles against human pathogenic bacteria, $C$ Control, $125 \mu \mathrm{g}, 250 \mu \mathrm{g}, 375 \mu \mathrm{g}, 4100 \mu \mathrm{g}$

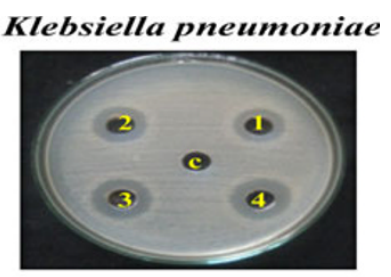

Salmonella typhi

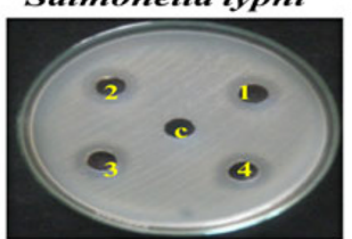

Vibrio cholerae

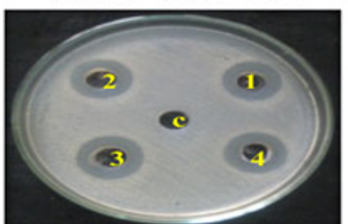


Table 1 Antibacterial activity (Zone of inhibition in $\mathrm{mm}$ ) of silver nanoparticles against human pathogens

\begin{tabular}{|c|c|c|c|c|c|c|c|}
\hline \multirow[t]{3}{*}{ S. no } & \multirow{3}{*}{$\begin{array}{l}\text { Concentration of silver } \\
\text { nanoparticles }(\mu \mathrm{g} / \mathrm{ml})\end{array}$} & \multicolumn{6}{|c|}{ Microorganism } \\
\hline & & \multicolumn{3}{|c|}{ Gram positive } & \multicolumn{3}{|l|}{ Gram negative } \\
\hline & & M. luteus & B. cereus & S. aureus & K. pneumoniae & S. typhi & V. cholerae \\
\hline 1 & 25 & 22 & 20 & 18 & 19 & 17 & 18 \\
\hline 2 & 50 & 24 & 21 & 20 & 21 & 18 & 20 \\
\hline 3 & 75 & 25 & 23 & 21 & 22 & 21 & 20 \\
\hline 4 & 100 & 26 & 24 & 22 & 23 & 22 & 21 \\
\hline
\end{tabular}
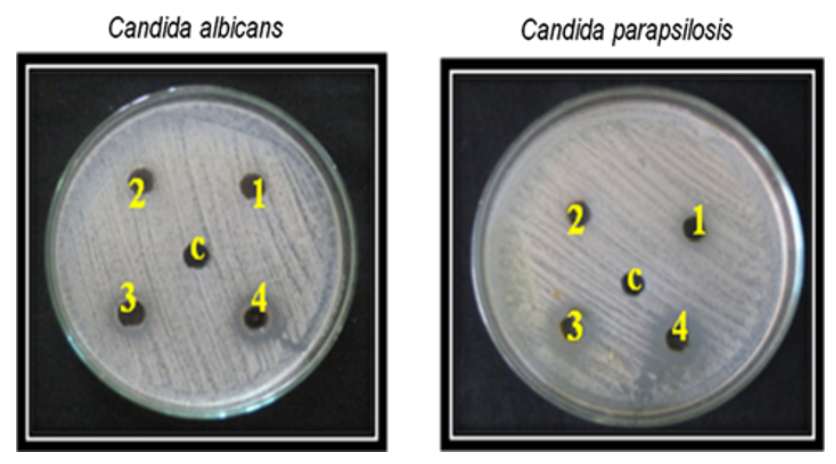

Fig. 9 Fungistatic and fungicidal assay of silver nanoparticles against human pathogenic fungi. $C$ Control, $125 \mu \mathrm{g}, 250 \mu \mathrm{g}, 3$ $75 \mu \mathrm{g}, 4100 \mu \mathrm{g}$

Mechanism of Ag nanoparticles was similar as described by Li et al. 2010b and Singhal et al. 2011 (Table 1).

Fungistatic and fungicidal assay of silver nanoparticles against human pathogenic fungi

Zone of inhibition in the plate showed that silver nanoparticles synthesized using Solanum trilobatum has the antifungal activity against test pathogens namely Candida albicans and Candida parapsilosis (Shahjahan et al. 2005; Bhutani et al. 2010). On comparison with the silver nitrate and filtrate silver nanoparticles outperformed in the fungicidal effect (Fig. 9; Table 2).

Table 2 Fungistatic and fungicidal assay (Zone of inhibition in $\mathrm{mm}$ ) of silver nanoparticles against human pathogenic fungi

\begin{tabular}{|c|c|c|c|}
\hline \multirow{2}{*}{$\begin{array}{l}\text { S. } \\
\text { no }\end{array}$} & \multirow{2}{*}{$\begin{array}{l}\text { Concentration } \\
(\mu \mathrm{g} / \mathrm{ml})\end{array}$} & \multicolumn{2}{|c|}{ Microorganism } \\
\hline & & $\begin{array}{l}\text { Candida } \\
\text { albicans }\end{array}$ & $\begin{array}{l}\text { Candida } \\
\text { parapsilosis }\end{array}$ \\
\hline 1 & 25 & 13 & 11 \\
\hline 2 & 50 & 16 & 11 \\
\hline 3 & 75 & 19 & 14 \\
\hline 4 & 100 & 20 & 19 \\
\hline
\end{tabular}
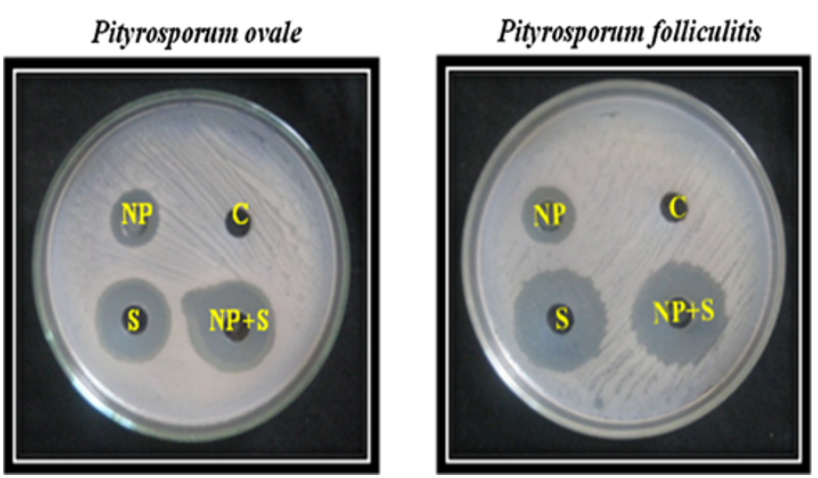

Fig. 10 Anti-dandruff activity of silver nanoparticles against human pathogenic dermatophytes. $C$ control, $N P$ nanoparticle and $S$ shampoo

Antidandruff activity

Among two different dandruff fungal species, nanoparticles showed maximum inhibitory activity (Ayyanar and Ignacimuthu 2011). 24 and $22 \mathrm{~mm}$ zone of inhibition were obtained by $P$. ovale and $P$. folliculitis, respectively (Fig. 10). The nanoparticles effectively inhibit all the test pathogen. The silver nanoparticles from Solanum trilobatum was chosen as best treatment for dandruff and chosen for further studies because of its high inhibitory activity (Fig. 11).

\section{Conclusion}

The bio-reduction of aqueous $\mathrm{Ag}^{+}$ions by the leaf extract of the Solanum trilobatum plant has been demonstrated. The reduction of the metal ions through leaf extracts leading to the formation of silver nanoparticles of fairly well-defined dimensions. In the present study we found that leaves can be good source for synthesis of silver nanoparticles. This green chemistry approach toward the synthesis of silver nanoparticles has many advantages such as, ease with which the process can be scaled up, economic viability, etc. Applications of such eco-friendly nanoparticles in bactericidal, wound healing and other medical applications, makes this method potentially exciting for the 
Fig. 11 Antifungal activity (Zone of inhibition in $\mathrm{mm}$ ) of silver nanoparticles against human pathogenic fungi causing dandruff. $C$ control, $N P$ nanoparticle and $S$ shampoo
Pityrosporum ovale

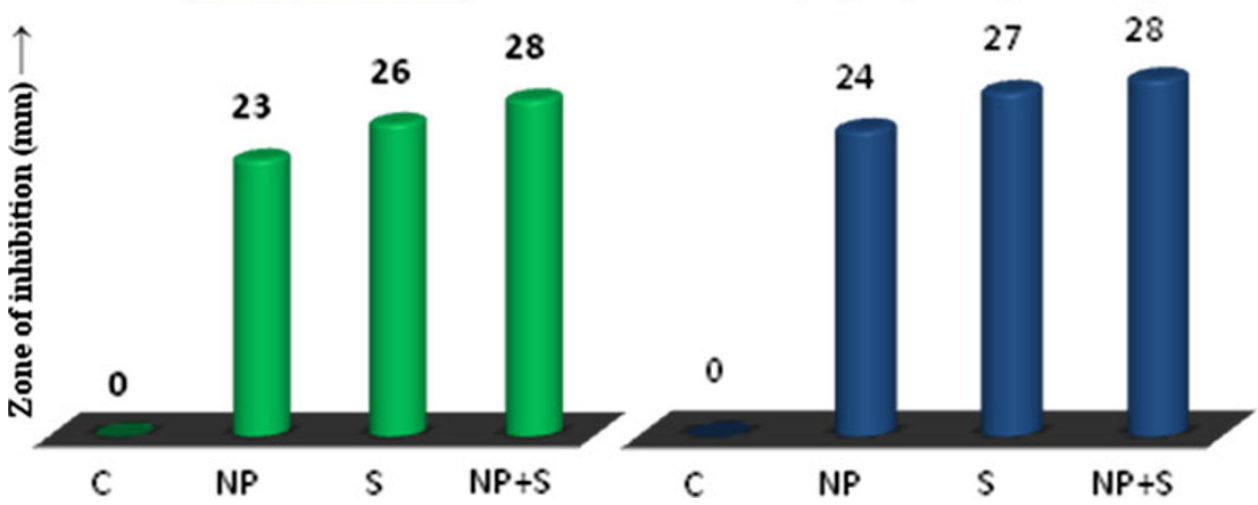

large-scale synthesis of other inorganic materials (nanomaterials). Antimicrobial studies of silver nanoparticles on human pathogen open a door for a new range of Antidandruff agents.

Acknowledgments Authors wish to thanks management and staff of GITAM University, Visakhapatnam, Andhra Pradesh, India and Armatsbiotek Training and Research Institute, Chennai, India, for providing research facilities and support for the research work. The authors are grateful to Dr. V. Ravichandran, Director, Department of Nuclear Physics, University of Madras, Chennai, India, for providing 'XRD' facilities. Authors are also pleased to acknowledge Dr. V. Sadasivam, Director, Department of Chemistry, Anna University, Chennai, India, for FTIR analysis and sincere thanks to Dr. S. Samapathkumar, Professor \& Head, Central workshop, Department of Mechanical Engineering, Anna University, Chennai, India, for their help in SEM measurements.

Open Access This article is distributed under the terms of the Creative Commons Attribution License which permits any use, distribution, and reproduction in any medium, provided the original author(s) and the source are credited.

\section{References}

Alanis AJ (2005) Resistance to antibiotics: are we in the postantibiotic era? Arch Med Res 36:697-705

Ansari AA, Alhoshan M, Alsalhi MS, Aldwayyan AS (2010) Prospects of nanotechnology in clinical immunodiagnostics. Sensors 10:6535-6581

Astruc D, Lu F, Aranzaes JR (2005) Nanoparticles as recyclable catalysts: the frontier between homogeneous and heterogeneous catalysis. Angew Chem Int Ed 44:7852-7872

Ayyanar M, Ignacimuthu S (2011) Ethnobotanical survey of medicinal plants commonly used by Kani tribals in Tirunelveli hills of western ghats, India. J Ethnopharmacol 134:851-864

Bahgat K, Ragheb AG (2007) Analysis of vibratinal spectra of 8-hydroxyquinoline and its 5, 7-dichloro, 5,7-dibromo, 5,7-diiodo and 5,7-dinitro derivatives based on density functional theory calculations. Cent Eur J Chem 5:201-220

Bee M, Djurado D, Combet J, Gonzalez MA (2002) Dynamics of camphor sulphonic acid: a quasielastic neutron scattering study. Chem Phys 277:211-224
Begum NA, Mondal S, Basu S, Laskar RA, Mandal D (2009) Biogenic synthesis of $\mathrm{Au}$ and $\mathrm{Ag}$ nanoparticles using aqueous solutions of black tea leaf extracts. Colloids Surf B 71:113-118

Bhutani KK, Paul AT, Fayad W, Linder S (2010) Apoptosis inducing activity of steroidal constituents from Solanum xanthocarpum and Asparagus racemosus. Phytomedicine 17:789-793

Brown CL, Bushell G, Whitehouse MW (2007) Nanogoldpharmaceutics (i) The use of colloidal gold to treat experimentallyinduced arthritis in rat models; (ii) Characterization of the gold in Swarna bhasma, a microparticulate used in traditional indian medicine. Gold Bull 40:245-250

Chudasama B, Vala AK, Andhariya N, Upadhyay RV, Mehta RV (2009) Enhanced antibacterial activity of bifunctional $\mathrm{Fe}_{3} \mathrm{O}_{4}-\mathrm{Ag}$ core-shell nanostructures. Nano Res 2:955-965

Cihlar J, Buchal A, Trunec M (1999) Kinetics of thermal decomposition of hydroxyapatite bioceramics. J Mater Sci 34:6121-6131

Citarasu T, Venkatramalingam K, Babu MM, Sekar RRJ, Petermarian M (2003) Influence of the antibacterial herbs, Solanum trilobatum, Andrographis paniculata and Psoralea corylifolia on the survival, growth and bacterial load of Penaeus monodon post larvae. Aquacult Int 11:581-595

Davies J, Davies D (2010) Origins and evolution of antibiotic resistance. Microbiol Mol Biol 74:417-433

Dick LA, McFarland AD, Haynes CL (2001) Metal film over nano sphere (MFON) electrodes for surface-enhanced Raman spectroscopy (SERS): improvements in surface nanostructure stability and suppression of irreversible loss. J Phys Chem B 106:853-860

Duncan TV (2011) Applications of nanotechnology in food packaging and food safety: Barrier materials, antimicrobials and sensors. J Colloid Interface Sci 363:1-24

Edwards HGM, Newton EM, Williams DDW, Coombes SR (2003) Molecular spectroscopic studies of lichen substances 1: parietin and emodin. J Mol Struct 648:49-59

Eiff CV, Becker K, Machka K, Stammer H, Peters G (2001) Nasal carriage as a source of Staphylococcus aureus bacteremia. N Engl J Med 344:11-16

Fendler JH (2001) Chemical self-assembly for electronic applications. Chem Mater 13:3196-3210

Galina J, Yin G, Ardo L, Jeney Z (2009) The use of immunostimulating herbs in fish. An overview of research. Fish Physiol Biochem 35:669-676

Giljohann DA, Seferos DS, Daniel L (2010) Gold nanoparticles for biology and medicine. Angew Chem Int Ed 49:3280-3294

Govindarajan M, Jebanesan A, Pushpanathan T (2008) Larvicidal and ovicidal activity of Cassia fistula Linn. leaf extract against filarial and malarial vector mosquitoes. Parasitol Res 102:289292 
Govindaraju K, Basha SK, Kumar V, Kumar G, Singaravelu G (2008) Silver, gold and bimetallic nanoparticles production using single-cell protein (Spirulina platensis) geitler. J Mater Sci 43:5115-5122

Hartmann A, Czauderna T, Hoffmann R, Stein N, Schreiber F (2011) An image analysis pipeline for high-throughput plant phenotyping. BMC Bioinformatics 12:148

Jahan MS, Vani G, Shyamaladevi CS (2011) Anti-carcinogenic effect of Solanum trilobatum in diethylnitrosamine induced and phenobarbital promoted heaptocarcinogenesis in rats. Asian J Biochem 6:74-81

Kamat PV (2002) Photophysical, photochemical and photocatalytic aspects of metal nanoparticles. J Phys Chem B 106:7729-7744

Kanchana A, Devarajan S, Ayyappan SR (2010) Green synthesis and characterization of palladium nanoparticles and its conjugates from Solanum trilobatum leaf extract. Nano Micro Lett 2:169176

Kanchana A, Kumar J, Reddy T, Mahesh V, Ayyappan SR, Nellore J (2012) Synthesis and characterization of chitosan and grape polyphenols stabilized palladium nanoparticles and their antibacterial activity. Colloids Surf B 92:254-261

Kerr IB, Araripe JR, Oliveira PC, Lenzi HL (1988) Paracoccidioisomycosis: a sequential histopathologic study of lesions in experimentally-infected rats. Rev Inst Med Trop Sao Paulo 30:336-350

Li JF, Huang YF, Ding Y (2010a) Shell-isolated nanoparticle enhanced raman spectroscopy. Nature 464:392-395

Li WR, Xie XB, Shi QS, Zeng HY, Yang YSOU, Chen YB (2010b) Antibacterial activity and mechanism of silver nanoparticles on Escherichia coli. Appl Microbiol Biotechnol 85:1115-1122

Lopez-Acevedo O, Kacprzak KA, Akola J (2010) Quantum size effects in ambient $\mathrm{CO}$ oxidation catalysed by ligand-protected gold clusters. Nat Chem 2:329-334

Lu AH, Salabas EL, Schuth F (2007) Magnetic nanoparticles: synthesis, protection, functionalization and application. Angew Chem Int Ed 46:122-124

Maier SA, Brongersma ML, Kik PG (2001) Plasmonics-a route to nanoscale optical devices. Adv Mater 13:1501-1505

Marimuthu S, Rahuman AA, Rajakumar G, Santhoshkumar T, Kirthi AV, Jayaseelan C, Bagavan A, Zahir AA, Elango G, Kamaraj C (2011) Evaluation of green synthesized silver nanoparticles against parasites. Parasitol Res 108:1541-1549
Mary EJ, Inbathamizh L (2012) Green synthesis and characterization of nano silver using leaf extract of Morinda pubescens. Asian J Pharm Clin Res 5:159-162

Nelson ML (2002) Modulation of antibiotic efflux in bacteria. Curr Med Chem Anti-Infect Agents 1:35-54

Nie S, Emory SR (1997) Probing single molecules and single nanoparticles by surface enhanced raman scattering. Science 275:1102-1106

Ozbay E (2006) Plasmonics: merging photonics and electronics at nanoscale dimensions. Science 311:189-193

Raghunandan D, Borgaonkar PA, Bendegumble B, Bedre MD, Bhagawanraju M, Yalagatti MS, Huh DS, Abbaraju V (2011) Microwave-assisted rapid extracellular biosynthesis of silver nanoparticles using carom seed (Trachyspermum copticum) extract and in vitro studies. Am J Anal Chem 2:475-483

Rosarin FS, Mirunalini S (2011) Nobel metallic nanoparticles with novel biomedical properties. J Bioanal Biomed 3:85-91

Saxena S, Gomber C (2010) Surmounting antimicrobial resistance in the millennium superbug: Staphylococcus aureus. Cent Eur J Med 5:12-29

Shahjahan M, Vani G, Shyamaladevi CS (2005) Effect of Solanum trilobatum on the antioxidant status during diethyl nitrosamine induced and phenobarbital promoted hepatocarcinogenesis in rat. Chem Biol Interact 156:113-123

Singhal G, Bhavesh R, Kasariya K, Sharma R, Singh RP (2011) Biosynthesis of silver nanoparticles using Ocimum sanctum (Tulsi) leaf extract and screening its antimicrobial activity. J Nanopart Res 13:2981-2988

Sun Y, Changhua AN (2011) Shaped gold and silver nanoparticles. Front Mater Sci 5:1-24

Wu H, Wu C, He Q, Liao X, Shi B (2010) Collagen fiber with surface-grafted polyphenol as a novel support for Pd (0) nanoparticles: synthesis, characterization and catalytic application. Mater Sci Eng 30:770-776

Zahir AA, Rahuman AA, Bagavan A, Santhoshkumar T, Mohamed RR, Kamaraj C, Rajakumar G, Elango G, Jayaseelan C, Marimuthu S (2010) Evaluation of botanical extracts against Haemaphysalis bispinosa Neumann and Hippobosca maculata leach. Parasitol Res 107:585-592

Zhang W, Qiao X, Chen J, Wang H (2006) Preparation of silver nanoparticles in water-in-oil AOT reverse micelles. J Colloid Interface Sci 302:370-373 